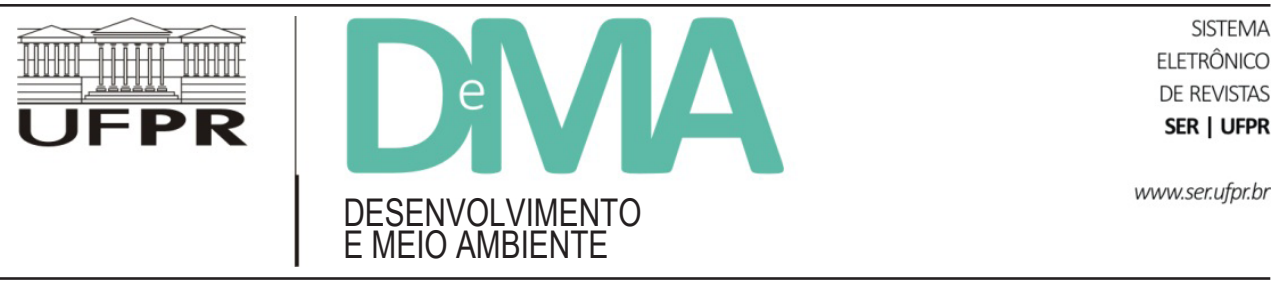

\title{
A deposição irregular de resíduos da construção civil no município de São Paulo: um estudo a partir dos instrumentos de políticas públicas ambientais
}

\section{The Illegal Disposal of the Construction Waste in the City of São Paulo: A Study Based on the Instruments of Environmental Public Policies}

\author{
Flávio Bordino KLEIN ${ }^{1 *}$, Sylmara Lopes Francelino GONÇALVES-DIAS ${ }^{1}$ \\ ${ }^{1}$ Universidade de São Paulo (USP), São Paulo, SP, Brasil. \\ *E-mail de contato: flabklein@gmail.com
}

Artigo recebido em 13 de julho de 2016, versão final aceita em 26 de janeiro de 2017.

RESUMO: A deposição irregular de resíduos da construção civil (RCC) em locais públicos tem sido uma problemática nos municípios brasileiros, causando diversos impactos ambientais e custos de limpeza pública às municipalidades. Dessa maneira, o objetivo do presente estudo foi entender os principais fatores que podem induzir os geradores e empresas de transporte ao descarte irregular de resíduos da construção civil (RCC) no município de São Paulo. O procedimento metodológico adotado foi a pesquisa descritiva, por meio da identificação e análise de variáveis e aspectos relacionados ao fenômeno empírico do descarte irregular de RCC. Como técnicas para coleta de dados, utilizou-se a pesquisa documental, com ênfase no Plano de Gestão Integrada de Resíduos Sólidos (PGIRS) do município, além de outros documentos legais, complementados pela revisão bibliográfica. Concluiu-se que os principais fatores relacionados ao descarte irregular nos logradouros e áreas públicas podem estar associados à variável renda, limitando os pequenos geradores de baixa renda a demandarem a locação de caçambas para o transporte desses resíduos, bem como à dificuldade da acessibilidade e custos logísticos até os pontos de entrega voluntária (PEVs). Há também falta de razoabilidade e critérios adequados na definição do pequeno e grande gerador. O estudo sugere que haveria a necessidade de melhoria em formulação e implementação dos instrumentos de políticas públicas para solução da problemática aqui analisada. Especialmente, recomenda-se que os serviços de coleta, transporte e tratamento dos RCC sejam ofertados sob regime de direito público - remunerados por meio de taxa precificada com base em critérios sociais e ambientais -, para maior controle sobre os geradores e empresas de transporte.

Palavras-chave: resíduos de construção civil (RCC); deposição irregular de resíduos; pontos de entrega voluntária (PEVs); descarte irregular de resíduos; município de São Paulo.

ABSTRACT: The illegal disposal of construction waste $(\mathrm{CW})$ in public places has been a problem in Brazilian municipalities, causing various environmental impacts and public cleaning costs to municipalities. Thus, the objective of this 
study was to analyze the main factors that can influence the generators and transport companies to illegal disposal of construction waste (CW) in São Paulo. The methodological procedure adopted was the descriptive research through the identification and analysis of variables and aspects related to the empirical phenomenon of irregular disposal of $\mathrm{CW}$. As techniques for data collection, we used the documentary research, with emphasis on the Plan of Integrated Solid Waste Management (PGIRS) of the municipality, and other legal documents, supplemented by literature review. It was concluded that the main factors related to the irregular disposal in public places may be associated with income, which limited the small low-income generators to require the rental container for the transport of waste, besides the difficulty of accessibility and logistic costs to the voluntary delivery points (VEPs). There is also a lack of reasonable and appropriate criteria in the definition of small and large generator. The work suggests that there would be a need for services of collection, transportation and treatment of $\mathrm{CW}$ to be offered under public law - paid through tax and priced through social and environmental criteria - for greater control over generators and transport companies.

Keywords: construction waste (CW); illegal disposal; voluntary delivery points (VEPs); illegal dumping; city of São Paulo.

\section{Introdução}

A construção civil é um importante segmento da indústria brasileira, estando associada ao crescimento econômico e social (IPEA, 2012). Por outro lado, quando comparada com outros setores produtivos, a construção civil é o principal consumidor de recursos naturais, sendo uma atividade geradora de impactos ambientais negativos significativos (Agopyan \& John, 2011).

À medida que os materiais extraídos para o setor da construção civil se movem ao longo do seu ciclo de vida, resíduos são gerados. E, quando gerenciados e dispostos incorretamente, continuam causando relevantes impactos ambientais negativos como degradação e poluição do solo, comprometimento dos corpos d'água e mananciais, obstrução dos sistemas de drenagem, intensificação de enchentes, degradação da paisagem urbana, ocupação de vias e logradouros públicos por resíduos, proliferação de moscas, baratas, ratos e outros vetores de importância sanitária nos centros urbanos (Pinto, 2005; Karpinsk et al., 2009; Brasil, 2010a; Agopyan \& John, 2011; Delongui et al., 2011; Lu \& Tam, 2013; Yeheyis et al., 2013).

Os resíduos da construção civil (RCC) ${ }^{1}$ representam a massa predominante de resíduos gerados em áreas urbanas. No Brasil, correspondem entre $50 \%$ a $70 \%$ quando comparados com o total de resíduos sólidos urbanos (RSU's) (IPEA, 2012). Os principais responsáveis pela geração de RCC são: (i) executores de reformas, ampliações e demolições - atividades raramente formalizadas com a solicitação de alvarás, mas que, no conjunto, consistem na fonte principal desses resíduos; (ii) construtores de edificações novas, com áreas de construção superiores a $300 \mathrm{~m}^{2}$, cujas atividades quase sempre são formalizadas; (iii) construtores de novas residências individuais, tanto aquelas de maior porte, em geral formalizadas, quanto as pequenas residências de periferia, quase sempre autoconstruídas e informais (Brasil, 2010b).

\footnotetext{
${ }^{1} \mathrm{Na}$ literatura, alguns autores como Carrijo (2005), Schneider (2003) e Karpinsk et al. (2009) fazem referência aos resíduos de construção e demolição (RCD), enquanto outros, como Delongui et al. (2011) e Jacobi \& Besen (2011), definem como resíduos da construção civil (RCC). No presente estudo, adotou-se esta última por ser a mesma definição usada pela Resolução CONAMA no 307/02 (CONAMA, 2002) e pelo Ministério do Meio Ambiente (Brasil, 2012).
} 
Historicamente, o poder público municipal enfrenta o problema da limpeza e recolhimento dos RCC depositados em locais inapropriados como logradouros públicos, canteiros, ruas, praças e margens de rios (IPEA, 2012). A incidência dos locais onde ocorre a deposição ${ }^{2}$ irregular de RCC é predominante nas periferias e áreas ocupadas por população de baixa renda das cidades brasileiras. Schneider (2003) identificou que as regiões de IDH (Índice de Desenvolvimento Humano) baixo e muito baixo no município de São Paulo concentravam o maior volume de deposição irregular, proveniente das regiões sul e leste da cidade. Resultados similares foram encontrados em Uberlândia-MG (Morais, 2006; Ribeiro \& Dias, 2013); em Passo Fundo-RS (Karpinsk et al., 2009); em Parnaíba-PI (Feijão Neto, 2010); em São José do Rio Preto-SP (Silva, 2012); e em Montes Claros-MG (Mourão et al., 2015).

No intuito de adotar diretrizes e procedimentos para redução, reaproveitamento e reciclagem dos RCC, o Conselho Nacional do Meio Ambiente (CONAMA, 2002) aprovou a Resolução n ${ }^{0}$ 307/02 que "estabelece diretrizes, critérios e procedimentos para a gestão dos resíduos da construção civil”. Uma das medidas para redução do descarte irregular de RCC tem sido a recomendação do Ministério do Meio Ambiente para implantação dos Pontos de Entrega Voluntária (PEVs) nos municípios (Brasil, 2012).

Os PEVs são locais públicos que disponibilizam gratuitamente equipamentos, a exemplo de caçambas, para a população descartar adequadamente os resíduos da construção civil, resíduos volumosos, resíduos domésticos da coleta seletiva e resíduos enquadrados na logística reversa obrigatória. Nesse sentido, os PEVs permitem transformar resíduos difusos em resíduos concentrados, reduzindo-se custos com a limpeza corretiva do descarte irregular e, concomitantemente, promovendo-se a precaução e a prevenção em relação aos impactos socioambientais dos diferentes resíduos. ${ }^{3}$

Especificamente em São Paulo, essas recomendações têm provocado uma significativa ampliação da oferta de PEVs à população residente na cidade. Apesar dos esforços da prefeitura para reduzir a deposição irregular de RCC por moradores, empresas e por pequenos transportadores, a problemática continua desafiadora. No ano de 2013, foram contabilizados cerca de 4.500 locais com deposição irregular de RCC e resíduos volumosos, e os gastos para limpeza desses "pontos viciados" continuam expressivos (São Paulo, 2014, p. 141).

Nesse contexto, este trabalho propõe responder a seguinte questão: como os instrumentos de políticas públicas ambientais estão relacionados com a deposição irregular de RCC em nível local? Partindo dessa questão, o objetivo do presente estudo foi entender os principais fatores que podem induzir os geradores e empresas de transporte à deposição irregular de resíduos da construção civil (RCC) no Município de São Paulo.

\section{Os Instrumentos de políticas públicas e as questões socioambientais}

O papel do formulador de políticas públicas é identificar ou criar instrumentos que resultem em soluções dos problemas considerados públicos. Os

\footnotetext{
${ }^{2}$ Neste estudo, o termo deposição irregular de resíduos foi utilizado como sinônimo de descarte irregular de resíduos, significando abandonar resíduos em locais inapropriados ("bota-fora” ou "pontos viciados”). Já o termo disposição de resíduos será usado como destinação adequada do resíduo. Neste estudo, a disposição de resíduos da construção civil quer dizer enviar para aterro de resíduos inertes.

${ }^{3}$ Conforme art. $6^{\circ}$, inciso I, da Política Nacional de Resíduos Sólidos - PNRS (Brasil, 2010c).
} 
instrumentos de políticas públicas são mecanismos utilizados para a produção da ação pública. São os meios, as ferramentas que o gestor público identifica no processo de formulação da política para execução das alternativas para solução do problema público.

Wu et al. (2014) dizem que algumas opções de políticas públicas deixam explícitas as deficiências não apenas sobre o que fazer, mas como fazer. Por exemplo, ao causar alteração adversa sobre a qualidade do meio ambiente, a poluição ${ }^{4}$ torna-se uma externalidade, visto que os agentes econômicos que a emitem impõem custos a outros agentes - cidadãos, consumidores, empresas [e o próprio Poder Público] (Mueller, 2007). Nesse caso, ao se adotar instrumentos econômicos como impostos, taxas ou tarifas (tributos) sobre o uso de recursos naturais ou sobre o lançamento dos dejetos ou resíduos, alterar-se-ia o preço (custo) do produto pelo sobrepreço embutido no processo produtivo, levando-se à internalização das externalidades e, portanto, seu nível de utilização (do recurso natural) ou o nível de lançamento de poluentes seriam afetados (Seroa da Motta, 2006). O agente responsável por tal atividade, ao arcar com a internalização da poluição, geraria receitas aos governos (pela arrecadação de tributos ambientais e por deixar de cobrir os gastos do tratamento da poluição antes realizados com recursos governamentais), que poderiam estimulá-lo a adotar inovações tecnológicas, seja na maior eficiência no uso de matérias-primas, seja na redução da carga poluidora.

Além disso, a emergência dos problemas ambientais urbanos obriga os formuladores de políticas públicas a considerarem os pesos variados da localização, distância, topografia, crescimento populacional, estrutura social do espaço urbano e o processo de seletividade ou segregação espacial (Coelho, 2001). Assim, as políticas governamentais criadas para incentivar ou obrigar os atores a adotarem comportamentos e tecnologias condizentes com a gestão integrada e adequada dos resíduos seriam implementadas por meio de instrumentos de comando e controle (regulações, normas e padrões de qualidade ambiental) ou de instrumentos econômicos (taxas, tarifas e impostos; subsídios e incentivos fiscais) (Seroa da Motta, 2006; Vergara \& Tchobanoglus, 2012). Também há os instrumentos informativos (campanhas de utilidade pública e acesso a informação), que, somados a estratégias de conscientização e sensibilização ou à criação de senso de dever moral, têm o objetivo de disseminar informações importantes e direcionar os comportamentos (Margulis, 1996).

No que tange aos primeiros, instrumentos de comando e controle (ICs), as regulações e normas embutidas na legislação ambiental [como a própria Resolução CONAMA no 307/02] buscam disciplinar o limite à emissão de poluentes ou as formas, tecnologias e procedimentos que o gerador deve utilizar para tratar a carga poluidora (Vergara \& Tchobanoglus, 2012). Os governos em diversos países têm implementado políticas públicas como leis, regulamentos e diretrizes para disciplinar as atividades da construção civil, com o intuito de reduzir os impactos ao meio ambiente e à saúde pública (Lu \& Tam, 2013).

Um dos limites à efetividade no cumprimento da legislação com base unicamente nos ICs é que,

\footnotetext{
${ }^{4}$ A poluição ambiental, em conformidade com a Política Nacional de Meio Ambiente (Brasil, 1981), seria pela violação ao art. $3^{\circ}$, inciso III, para quaisquer atividades que causem alteração adversa da qualidade ambiental à saúde, segurança ou bem-estar à população, às atividades sociais e econômicas, à biota, às condições estéticas ou sanitárias do meio ambiente ou lancem matérias ou energia em desacordo com os padrões ambientais estabelecidos.
} 
na maioria das vezes, esses limites são orientados por tecnologias, padrões e processos impostos de forma pouco flexível a todos os usuários e, muitas vezes, sem qualquer tipo de diferenciação (Margulis, 1996; Seroa da Motta, 2006). Logo, como os ICs não consideram os custos individuais de cada usuário ou gerador de poluentes, mesmo com estruturas de custo completamente diferentes, tais geradores acabam recebendo o mesmo tratamento.

Por outro turno, os instrumentos econômicos (IEs) podem ser outra maneira de influenciar na quantidade ou composição da geração de resíduos sólidos. Conhecido como o sistema de taxação denominado "pague conforme você descarta" ou pay as you throw (PAYT), permite aplicar taxas sobre os consumidores, conforme a quantidade de resíduos gerada. Tal sistema, já existente na Dinamarca e na Alemanha, tem sido implementado em outros países e regiões como na União Europeia, Austrália, Coréia, Canadá, México e Japão, sendo associado com a redução na geração de resíduos, por influenciar no comportamento da população e, assim, levando-a a adotar práticas como a redução do descarte de resíduos e o emprego alternativo da reciclagem e da compostagem dos resíduos orgânicos (Vergara \& Tchobanoglus, 2012, p. 296).

\section{Os serviços públicos e os critérios para precificação}

Os serviços públicos ${ }^{5}$ relacionados à gestão de resíduos sólidos e limpeza urbana podem ser executados diretamente pelo Estado ou transferidos por meio de concessão ou permissão ou por contratos administrativos com o setor privado. No caso da concessão ou permissão, o exercício da atividade pública é juridicamente transferido para outro, isto é, o Estado atribui a alguém o direito para se relacionar diretamente com os administrados [usuários] aos quais prestará a atividade, remunerando-se, pela exploração do serviço, por meio de tarifa (Mello, 2006). Carvalho Filho (2006) menciona como exemplos a exploração de atividades como transporte e energia elétrica.

Há, porém, outras situações de prestação de serviços em que o prestador, por meio de um contrato administrativo, é um mero executor: não lhe são transferidos poderes públicos (como no caso da concessão ou permissão). Nesses casos, o Estado apenas utiliza o contratado para executar uma tarefa ou atividade, sem investi-lo em titulação para se relacionar diretamente com os administrados [usuários]. As relações transitam apenas entre o Estado e o contratado e este será remunerado diretamente pelo Estado pela execução do serviço que foi contratado.

É o que ocorre, por exemplo, com a coleta de lixo domiciliar no município de São Paulo e, aliás, em geral, em múltiplos municípios. Trata-se de um serviço público como é evidente. E é prestado ao Poder Público por empresas privadas. Sem embargo, trata-se de um simples contrato de prestação de serviços e não concessão de serviço público (Mello, 2006, p. 5).

No caso de os serviços serem de caráter obrigatório como a coleta de lixo, isto é, impostos aos administrados e, dada a titularidade, continuarem sob o domínio do Estado, devem ser remunerados por taxa, por ser uma espécie de tributo previsto para esse fim (Carvalho Filho, 2006). Tal tipo de

\footnotetext{
5 “[...] toda atividade prestada pelo Estado ou por seus delegados, basicamente sob regime de direito público, com vistas à satisfação das necessidades essenciais e secundárias da coletividade". (Carvalho Filho, 2006, p. 267, grifos no original).
} 
tributo é utilizado como uma contraprestação dos particulares ao Estado pela oferta de serviços públicos. Nos termos do art. 145, inciso II, da Constituição Federal de 1988, taxa é um tributo decorrente da atuação estatal, seja para colocar um serviço à disposição do contribuinte, serviço este específico, seja em razão da atividade fiscalizadora do Estado (Figueiredo, 2004).

Considerando que uma parcela dos geradores pode ser induzida a descartar irregularmente os resíduos em decorrência do sobrepreço instituído pela taxa (Vergara \& Tchobanoglus, 2012), há a necessidade de fixar faixas de precificação de acordo com o tipo de poluente, grau de impacto e capacidade de pagamento do usuário. Como ressaltaram Sayago et al. (1998), as taxas ambientais devem ser graduadas conforme o custo dos serviços públicos ambientais relacionados com a carga poluidora gerada pelos contribuintes, podendo, ainda, gerar significativas receitas públicas para o custeio das tarefas administrativas. No contexto brasileiro, é necessário, sob a ótica da oferta de serviços públicos e da imposição de taxas, considerar alguns princípios - eficiência, modicidade, benefício, capacidade de pagamento, equidade e universalidade - apresentados na Tabela 1.

\section{Procedimentos metodológicos}

O tipo de pesquisa desenvolvida foi a descritiva (Cervo et al., 2007). Para o levantamento e a análise de dados, utilizou-se a pesquisa documental (Calado \& Ferreira, 2005), que compreendeu duas etapas: a de recolha e a de análise de conteúdo.

A primeira etapa foi caracterizada pelo levantamento e adoção de uma estratégia de seleção de dados pertinentes ao objetivo de estudo. O recolhimento do material ocorreu no portal Google, Web of Science e Scielo. Iniciou-se pela busca por documentos, leis e normas do nível local e federal no que tange à gestão de resíduos da construção civil.

Do nível federal, foram utilizados os seguintes documentos: (i) a Resolução CONAMA no 307/02 (CONAMA, 2002) e (ii) a Política Nacional de Resíduos Sólidos (PNRS) (Brasil, 2010c).

Do nível local, foram selecionados: (i) o Plano de Gestão Integrada de Resíduos Sólidos do Município de São Paulo (PGIRS), (ii) os mapas de uso e ocupação do solo, (iii) a Lei Municipal $n^{\circ}$ 13.478/02 (São Paulo, 2002), (iv) a Lei Municipal $n^{\circ} 14.803 / 2008$ (São Paulo, 2008).

Em seguida, foi realizada a busca, nas bases de dados eletrônicas nacionais no Scielo, por pa-

TABELA 1 - Alguns dos princípios que devem nortear os custos dos serviços públicos

\begin{tabular}{ll}
\hline \multicolumn{1}{c}{ Princípios } & \multicolumn{1}{c}{ Diretrizes e fundamentos gerais } \\
\hline Eficiência & $\begin{array}{l}\text { Refere-se ao uso de processos tecnológicos, de modo que a execução por parte da Administração Pública seja } \\
\text { a mais proveitosa com o menor dispêndio; pode também referir-se à qualidade do serviço prestado ao cidadão, } \\
\text { compreendendo a oferta de bens e serviços de maneira ágil, tempestiva e sem morosidade. }\end{array}$ \\
\hline Modicidade & $\begin{array}{l}\text { O Poder Público deve avaliar o poder aquisitivo do usuário para que, por dificuldades financeiras, não seja ele } \\
\text { cerceado do universo de beneficiários do serviço. }\end{array}$ \\
\hline Benefício & O indivíduo deve contribuir com uma quantia proporcional ao benefício obtido pelo serviço público. \\
\hline $\begin{array}{l}\text { Capacidade de } \\
\text { pagamento }\end{array}$ & O ônus tributário deve recair de acordo com a capacidade de pagamento do indivíduo. \\
\hline $\begin{array}{l}\text { Equidade e } \\
\text { universalidade }\end{array}$ & “....a possibilidade de atender desigualmente os que são desiguais, priorizando aqueles que mais necessitam para \\
\hline
\end{tabular}

FONTE: elaboração própria a partir de Carvalho Filho (2006), Paiva, C. \& Paiva, S. (2009) e Brasil (2014). 
lavras-chave ("resíduos" + "construção civil" ou "construção e demolição" + "descarte irregular" + “deposição irregular”). Como não foi encontrado nenhum resultado, optou-se por uma pesquisa nacional mais abrangente, por meio do Google, por palavras-chave (resíduos + "construção civil" ou "construção e demolição" + "descarte irregular" ou "deposição irregular" + "impactos ambientais" + CONAMA + PDF). Buscou-se digitalizá-las com a maior combinação possível para otimização dos resultados, dos quais foram analisadas e selecionadas somente as primeiras 10 páginas da busca, sendo excluídos os arquivos de monografias (TCC), sites e documentos oficiais não acadêmicos.

Para a literatura internacional, foram digitadas de maneira isolada e combinadas no Web of Science por palavras-chave: construction waste + "illegal dumping", com 14 resultados, e "construction waste" + impact + disposal, obtendo-se 32 resultados. Apesar dos achados, muitas dessas referências não estavam disponíveis para consulta.

Finalmente, houve a leitura e seleção das teses, dissertações e artigos nacionais e internacionais aqui utilizados.

$\mathrm{Na}$ segunda etapa, realizou-se a análise documental propriamente dita. A construção das matrizes analíticas foi orientada pelas recomendações de Calado \& Ferreira (2005) e Strauss \& Corbin (2008). Após a categorização temática dos documentos pesquisados e complementados pela pesquisa bibliográfica, os dados coletados foram reduzidos, categorizados e analisados, considerando-se: (i) a definição e critérios para o pequeno e grande gerador de RCC; (ii) as formas de destinação desses resíduos utilizadas pelos geradores: coleta regular pela prefeitura, PEVs, locação de caçambas ou descarte irregular; (iii) as formas de execução e precificação dos serviços de coleta e transporte de RCC por meio da locação de caçambas; e (iv) a renda da população e a relação com o tipo de ocupação do solo.

\section{A problemática e a natureza dos $R C C$ : resultado do levantamento da literatura nacional e internacional}

Os resíduos referentes à limpeza urbana ${ }^{6}$ possuem diversas origens e características em termos de massa, volume e aspectos físicos e químicos. Pode-se incluir desde os mais comuns como papéis, plásticos, vidros, metais e orgânicos descartados por pedestres e transeuntes, seja corretamente em coletores urbanos como cestos e tambores (lixeiras), seja descartados de maneira incorreta, poluindo e degradando diretamente praças, parques, ruas e avenidas, carreados pelas águas pluviais para rios, oceanos e tantos outros domínios difusos. ${ }^{7}$

Os resíduos da construção civil (RCC), apesar da característica e composição muito diversa dos

\footnotetext{
${ }^{6}$ Os resíduos sólidos urbanos (RSU) são classificados conforme Decreto Federal no 7.217/2010 (Brasil, 2010d, art. 12): (i) domésticos: gerados em residências, em estabelecimentos comerciais, industriais e de serviços (desde que a quantidade e qualidade - em termos de composição física e química - sejam similares aos resíduos domésticos por decisão do poder público municipal); e (ii) resíduos de limpeza urbana: estes referentes aos resíduos de natureza predominantemente difusa e, portanto, de competência e responsabilidade do poder público como os serviços públicos de varrição, raspagem e atividades de capina em vias e logradouros públicos, remoção de podas de árvores, desobstrução de bueiros e limpeza de resíduos oriundos de feiras livres, entre outros.

${ }^{7}$ De acordo com o Programa das Nações Unidas para o Meio Ambiente (UNEP, 2014), anualmente, há uma grande quantidade de resíduos, como plásticos, que são carreados até os oceanos, em decorrência da falta ou gestão inadequada de resíduos sólidos das áreas urbanas. Esses resíduos, sendo persistentes em ambientes aquáticos, são levados para grandes distâncias pelas correntes oceânicas, causando diversos impactos adversos como mortalidade e contaminação química da fauna marinha pela ingestão de pequenas partículas de plásticos.
} 
resíduos domésticos, também integram os serviços de limpeza urbana de duas maneiras: quando descartados pelo gerador em locais regulares, por meio dos PEVs, ou quando descartados em locais irregulares como calçadas, logradouros públicos, terrenos abandonados e margens de cursos d'água, sendo, também, de natureza difusa e gerador indeterminado.

Convencionalmente, os PEVs, sendo locais de uso público e gratuito, são identificados para receber resíduos de diversos tipos, dos quais são exemplos os de construção civil, resíduos volumosos, resíduos domésticos da coleta seletiva e resíduos enquadrados na logística reversa obrigatória. ${ }^{8}$ Preferencialmente, devem estar em locais de grande afluxo de pessoas e de fácil acesso (Brasil, 2012).

A oferta de pontos de entrega voluntária (PEVs) como estratégia para reduzir o descarte irregular, apesar de sua relevância, muitas vezes, tem uma efetividade limitada. A abordagem da literatura nacional e internacional à prevenção do descarte irregular e para a redução da geração, reaproveitamento e reciclagem de resíduos mostrou-se diferenciada. No âmbito dos estudos em cidades brasileiras, Ribeiro \& Dias (2013, p. 97), ao diagnosticarem os locais de descarte irregular em Uberlândia (MG), afirmam que “... no bairro já existe um Ecoponto, que deveria ser ponto de deposição regular, localizado aproximadamente $500 \mathrm{~m}$ dos demais [locais com descarte irregular]". Silva (2012), ao analisar o uso dos PEVs no município de São José do Rio Preto, identificou que, do total de 16 equipamentos públicos existentes, haveria deposição irregular próxima a 12 ecopontos. Já no município de Passo Fundo (RS),
[...] as deposições irregulares dos RCD também provêm de obras realizadas pela população de baixa renda, o que acontece normalmente por autoconstrução de munícipes que não dispõem de recursos financeiros para a contratação das empresas coletoras que atuam no setor (Karpinsk et al., 2009, p. 106).

Depreende-se que, se o gerador tiver dificuldades para transportar esses resíduos até um ecoponto mais próximo, a outra alternativa (ambientalmente correta) seria a contratação de transporte particular via locação de caçambas; nessa situação, a variável renda deve também ser considerada como indiretamente causadora da deposição irregular.

A externalização dos custos com a coleta e transporte adequado dos RCC por meio da deposição irregular ocorre, sobretudo, nas áreas periféricas das cidades brasileiras. Feijão Neto (2010) identificou que o descarte irregular de RCC na cidade de Parnaíba-PI é originado sobretudo das pequenas obras informais, não sendo controlado pelo Poder Público. Morais (2006) salienta que, apesar da existência de Centrais de Entulho (PEVs) para o recebimento de RCC na cidade de Uberlândia-MG, uma quantidade significativa desses resíduos é descartada clandestinamente, sendo a maior parte nos bairros periféricos e de baixa renda. Nesses bairros, sendo comum a prática da construção informal, tanto de pequenas reformas como autoconstrução, a deposição dos RCC é feita pelos próprios geradores ou por pequenos coletores (Morais, 2006). Em Montes Claros - MG, outros pontos críticos de deposição irregular foram identificados:

[...] pôde-se notar que essas áreas estão localizadas na maioria, em bairros periféricos onde há um número

\footnotetext{
${ }^{8}$ De acordo com o art. 33, incisos I a IV da PNRS, os resíduos enquadrados na logística reversa obrigatória seriam as embalagens de agrotóxicos, pilhas e baterias, pneus, embalagens de óleos lubrificantes, lâmpadas (fluorescentes, de vapor de sódio e mercúrio e de luz mista) e eletroeletrônicos.
} 
maior de vazios urbanos e ainda por falta de espaços apropriados outros pontos da cidade estão sendo usados para o descarte [irregular] de RCD (Mourão et al., 2015, p. 258).

A literatura internacional também destaca o contínuo aumento da geração de RCC e, concomitante, a tendência à redução de áreas disponíveis para serem usadas como aterros. Entretanto, os estudos abordam com maior ênfase os instrumentos econômicos capazes de lidar com a problemática ambiental. Hao et al. (2008) destacam que o governo de Hong Kong aprovou em 2005 um programa de cobrança para geração e disposição final de resíduos da construção civil, estabelecendo faixas de precificação muito maiores para o gerador que envia esses resíduos para aterros e, ao mesmo tempo, reduzindo a taxa de cobrança para o envio às usinas de beneficiamento que realizam o reaproveitamento ou reciclagem desses materiais. $\mathrm{O}$ uso de taxas diferenciadas para incentivar a reciclagem de RCC e assim reduzir a demanda por aterros é também adotado por alguns países da União Europeia e da Ásia. Na Coreia do Sul, por exemplo, após a implementação do programa de cobrança sobre aterros em 1995, houve uma redução de aproximadamente 30\% no total de resíduos antes dispostos em aterros e, em Taiwan, a redução chegou a 40\% após a adoção da cobrança em 2002 (Hao et al., 2008).

No Reino Unido, há o uso de instrumentos regulatórios, econômicos e voluntários para o desempenho ambiental e social na gestão de resíduos da construção civil (Osmani, 2012). Como incentivo para reduzir o volume enviado para aterros, desde 2008, foi instituída uma taxa com o valor de $£ 56$ (com base em 2011) para cada tonelada disposta em aterros; para os grandes geradores, há a obrigatoriedade da elaboração e execução do Site Waste Management Plans Regulations [equivalente ao Plano de Gerenciamento de Resíduos Sólidos determinado pela PNRS (Brasil, 2010c)]: é exigido para projetos de construção que excedam o valor de $£ 300.000$ (Osmani, 2012, p. 38).

Se, por um lado, tal sistema de taxação tem tido amplo sucesso nesses países na redução dos resíduos enviados para aterros por outro, também tem sido associado com o aumento do despejo irregular (Vergara \& Tchobanoglus, 2012). Conforme salientam Yu et al. (2013), um dos impactos negativos após a implementação do programa de cobrança de RCC para a disposição em aterros foi o aumento significativo do descarte irregular: o número de ocorrências em Hong Kong passou de 365 casos em 2005 para 1.587 casos em 2006, sendo difícil “...obter a prova concreta [do responsável] pelo descarte irregular" (Yu et al., 2013, p. 140, tradução nossa).

Apesar de maior rigidez quando comparado com os instrumentos econômicos, leis e regulamentos possuem grande relevância e impacto em restringir e determinar ações necessárias para os agentes poluidores. A ausência de leis e regulamentos que estabeleçam diretrizes gerais para a gestão de RCC em âmbito nacional pode limitar o combate à poluição e à prevenção da geração de resíduos entre municípios e regiões de um mesmo país. Diferentemente do Brasil, que instituiu em 2002 a Resolução CONAMA n ${ }^{\circ}$ 307, com abrangência em todo o território nacional (CONAMA, 2002), de acordo com Yeheyis et al. (2013, p. 84, tradução nossa), no Canadá, até aquela data, não havia "[...] uma regulação ou legislação federal que determine a implementação de medidas para reduzir a geração de RCC'. Naquele país, ações locais para a gestão e controle sobre os RCC são instituídas e regulamentadas apenas por leis municipais (Yeheyis et al., 2013). A Tabela 2 apresenta uma síntese da busca aqui empreendida. 


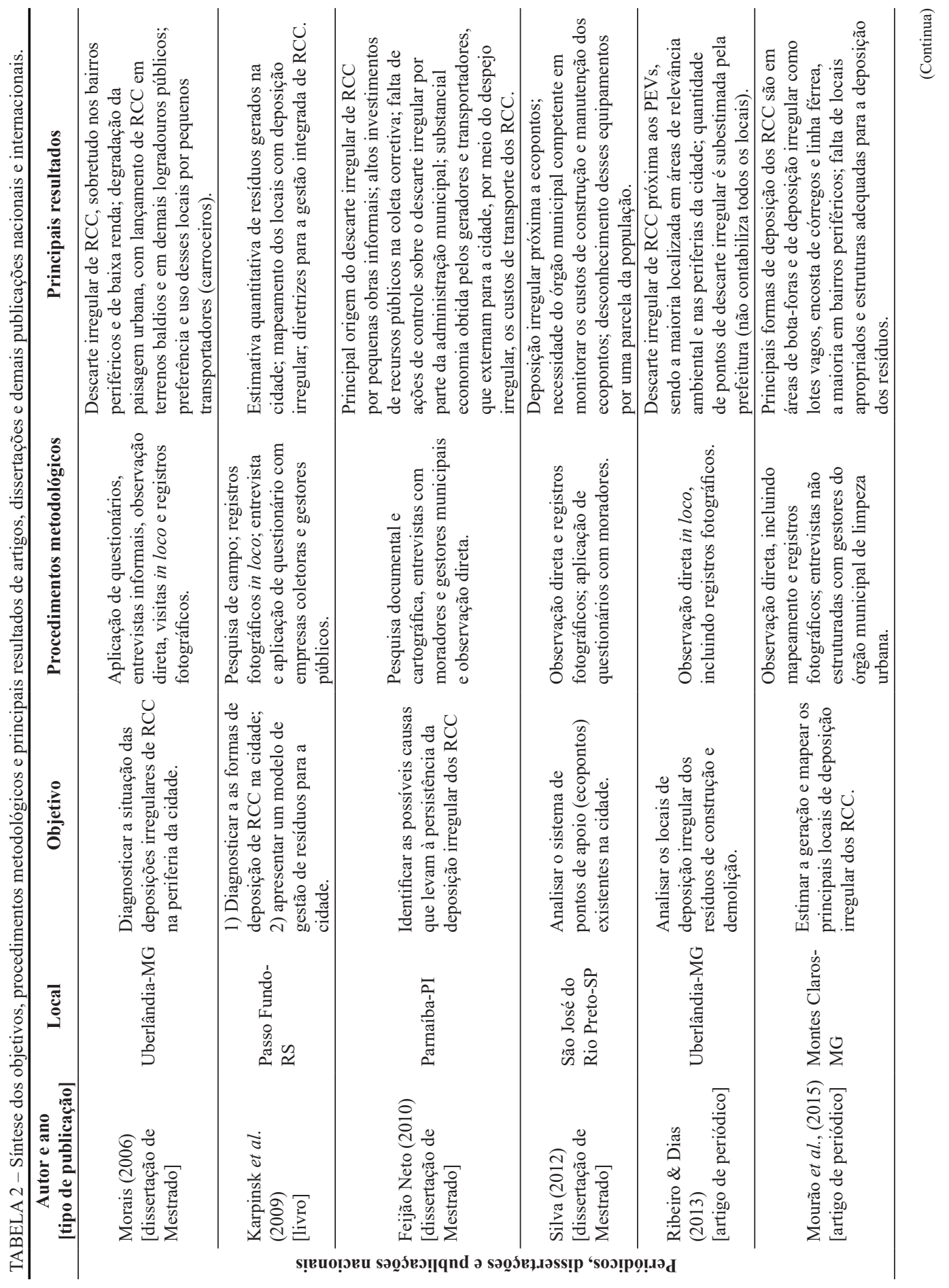




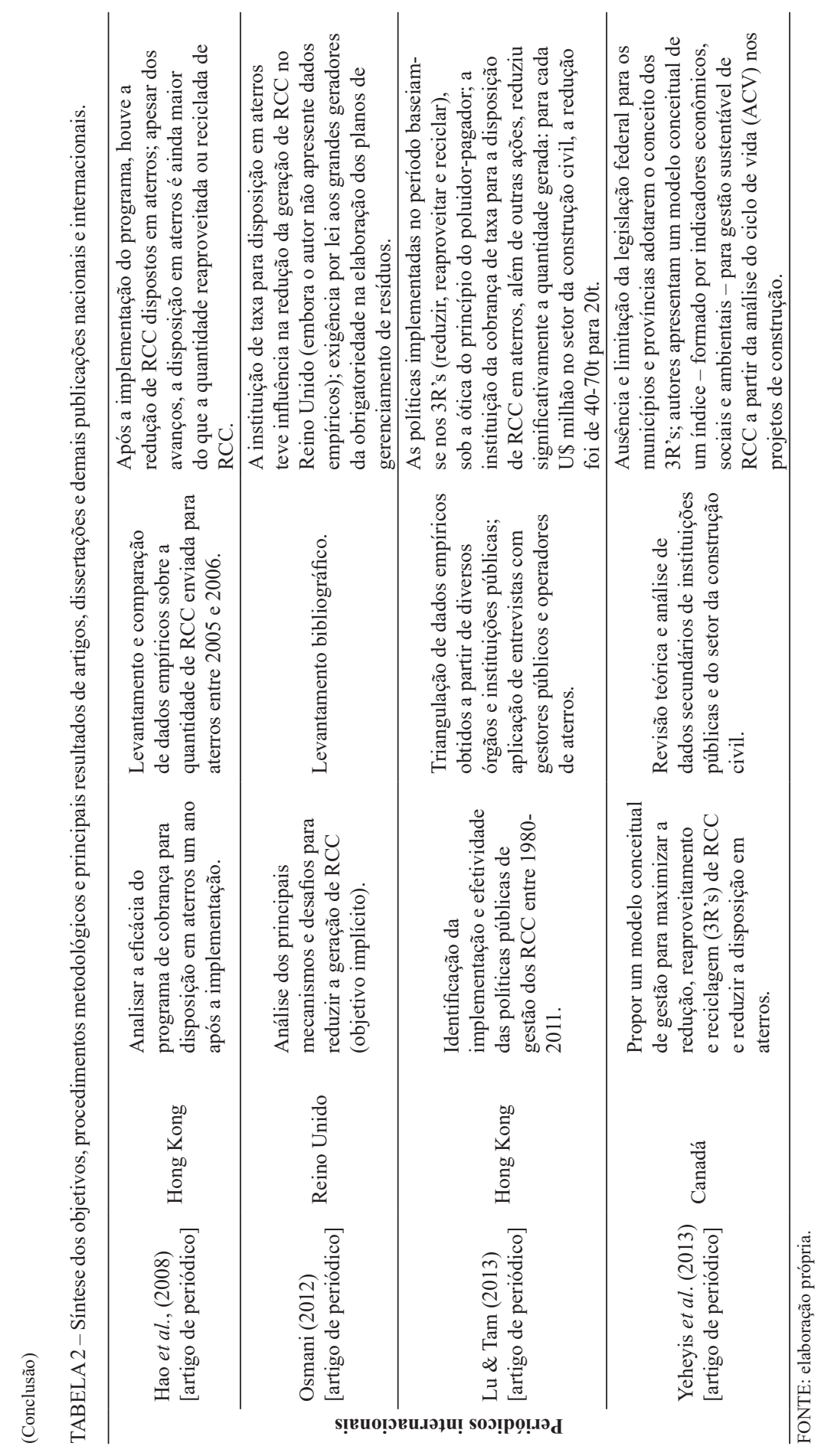




\section{O Município de São Paulo e a deposição irregular de RCC}

No ano de 2013, existiam na cidade de São Paulo cerca de 77 pontos de entrega voluntária - PEVs e foram contabilizados em torno de 4.500 locais (pontos viciados) com deposição irregular de RCC e resíduos volumosos descartados por moradores, empresas e por pequenos transportadores. Apesar de haver uma previsão de 140 ecopontos até o final de 2016 e de 300 até o ano 2020, não há informações e dados suficientes que possam garantir se e em que grau a ampliação dos PEVs poderá contribuir para a diminuição dos pontos viciados. Esse cenário representa um problema crescente à municipalidade.

Os pontos viciados demandam um processo continuado de limpeza corretiva por parte da prefeitura e, uma vez recolhidos, recebem em pouco tempo outra carga e se transformam em ambientes de criação de vetores de doenças e risco de acidentes, além de degradar a paisagem urbana (São Paulo, 2014, p. 137). Assim, os gastos da Prefeitura de São Paulo com os serviços de limpeza urbana para coleta, remoção, transporte, triagem e disposição final dos resíduos oriundos de ecopontos e pontos viciados são bastante expressivos. Em 2012, a retirada de 532 mil toneladas desses locais custou $\mathrm{R} \$$ 50,8 milhões ao cofre público municipal (São Paulo, 2014, p. 145). Mais detalhes na tabela 3.

Basicamente, para a coleta e destinação dos RCC e resíduos volumosos, são três as possibilidades aos munícipes. Para os RCC, a prefeitura pode incluir, na coleta domiciliar convencional (resíduos domésticos coletados porta a porta), até $50 \mathrm{~kg} /$ dia de entulho por imóvel e até 200 litros/dia de resíduos volumosos, desde que fragmentados e
TABELA 3 - Valor gasto em 2012 pela Prefeitura de São Paulo para a coleta, remoção, transporte, triagem e disposição final de resíduos dos pontos viciados e ecopontos

\begin{tabular}{lcc}
\hline \multicolumn{1}{c}{ Serviço prestado } & $\begin{array}{c}\text { Valor gasto } \\
\text { (em R\$ } \\
\text { milhões/ ano) }\end{array}$ & Valores /unidades \\
\hline limpeza dos pontos viciados & $\begin{array}{c}\mathrm{R} \$ 21,50 \\
\text { milhões }\end{array}$ & $\begin{array}{c}4.500 \text { pontos } \\
\text { viciados }\end{array}$ \\
\hline limpeza e manutenção dos & $\begin{array}{l}\mathrm{R} \$ 9,80 \\
\text { milhões }\end{array}$ & 54 ecopontos \\
\hline ecopontos & $\begin{array}{c}\mathrm{R} \$ 19,55 \\
\text { milhões }\end{array}$ & 3 aterros \\
\hline Aterros privados para & $\begin{array}{c}\mathrm{R} \$ 50,80 \\
\text { milhões }\end{array}$ & 532 mil toneladas ${ }^{(b)}$ \\
\hline Total & & \\
\hline
\end{tabular}

FONTE: São Paulo (2014).

(a) São 3 aterros privados: Riúma, situado no distrito de Pirituba; CTR Lumina, situado no distrito do Grajaú; e Itaquareia, situado no município de Itaquaquecetuba.

(b) Do volume total, cerca de $25 \%$ vieram dos Ecopontos, e $75 \%$, das deposições irregulares.

devidamente acondicionados (enquadrado como pequeno gerador). Acima dessa quantidade, o próprio gerador deve providenciar a remoção e transporte, recorrendo opcionalmente a duas possibilidades: (i) destinar pequenos volumes desses resíduos nos Ecopontos (opção limitada a no máximo $1 \mathrm{~m}^{3}$ de RCC e volumosos/descarga9; ou (ii) contratar empresas que operam com caçambas cadastradas pela administração municipal (São Paulo, 2008).

Observa-se, portanto, uma gradação nas possibilidades de destinação desses resíduos conforme a quantidade e volume gerados. No caso da geração de até $50 \mathrm{~kg} /$ dia de RCC ou 200 litros/dia de resíduos volumosos, o serviço é executado pela própria prefeitura. Já para quantidades superiores (já sendo enquadrado como grande gerador), devem ser analisados os procedimentos obrigatórios para contratação de caçambas para transporte ou, alternativamente, o uso gratuito dos ecopontos. A obrigatoriedade (em termos legais) da contratação

\footnotetext{
${ }^{9}$ Conforme art. $1^{\circ}$, inciso VIII, da Lei Municipal no 14.803/2008 (São Paulo, 2008).
} 
de caçambas para o transporte é definida pela Lei Municipal $n^{\circ} 13.478 / 02$, no art. 141 , caput, e art. $1^{\circ}$, inciso II, do Decreto Municipal $n^{\circ} 48.251 / 07$, para quantidades acima de $50 \mathrm{~kg} /$ dia de RCC, terra e resíduos volumosos (resíduos inertes). Porém, a partir de 2008, com a Lei Municipal no 14.803, passou-se a incluir outra alternativa aos geradores (além da contratação de caçambas) para destinação de RCC e resíduos volumosos. Trata-se da possibilidade de disposição de tais resíduos nos PEVs, em volume inferior a $1 \mathrm{~m}^{3} /$ descarga (São Paulo, 2008).

O uso dos ecopontos (PEVs), sem sombra de dúvida, é um importante avanço como instrumento tecnológico integrante do gerenciamento de resíduos sólidos urbanos, por permitir que qualquer cidadão possa descartá-los de forma ambientalmente correta, priorizando, dessa maneira, os princípios da prevenção e precaução, conforme art. $6^{\circ}$, inciso I, da Política Nacional de Resíduos Sólidos (PNRS). No entanto, considerar somente o uso dos PEVs como instrumento para eliminar o descarte irregular deve ser avaliado com cautela, uma vez que algumas variáveis como a distância, topografia, localização e formas de transporte (incluindo existência ou não de veículo próprio) inerentes à acessibilidade dos ecopontos poderão limitar o uso desses equipamentos por uma parcela expressiva da população. Se o custo logístico do transporte dos RCC até os PEVs for elevado, resta ao pequeno gerador a opção de descartá-los por meio da locação de caçambas.
No ano de 2010, o preço médio para alugar uma caçamba em São Paulo, segundo notícia do Jornal Folha, ${ }^{10}$ era de R\$220,00. Naquele mesmo ano, de acordo com a Lei Federal $n^{\circ} 12.255 / 10$, o salário mínimo era de $\mathrm{R} \$ 510,00$. Portanto, o custo médio da locação de caçamba representava um pouco mais de $\mathbf{4 0} \%$ de um salário mínimo em 2010. Esse custo é extremamente elevado para as famílias de menor poder aquisitivo. ${ }^{11}$ Conforme Jacobi (2004, p. 171):

O crescimento de São Paulo criou padrões urbanos similares aos de outras cidades latino-americanas, caracterizadas por grandes disparidades de saúde e status socioeconômico. A periferia da cidade não é provida de serviços urbanos básicos e tem sido ocupada pelos grupos de renda menos privilegiados.

Além do expressivo número de pontos viciados pelo município, existe uma enorme diversidade relacionada ao nível de renda e tipo de ocupação do solo, conforme mapa do município (Figura 1), que apresenta a distribuição da renda média familiar. Observa-se que há uma diminuição da renda conforme se avança em direção às periferias do município.

Ao se sobrepor o mapa (Figura 1) com o diagnóstico dos pontos viciados (Figura 2), observa-se que a grande predominância desses locais irregulares se localiza nas áreas com menor renda familiar. Esse diagnóstico atual reflete a análise de Schneider (2003). O autor identificou que regiões

\footnotetext{
${ }^{10}$ Bergamin Jr., G. São Paulo tem 5000 caçambas espalhadas pela cidade. Folha de São Paulo: São Paulo,13/09/2010. Disponível em: <http:// www1.folha.uol.com.br/saopaulo/796904-sao-paulo-tem-5000-cacambas-espalhadas-pelas-ruas-da-cidade.shtml>. Acesso em 03 05.2015.

${ }^{11}$ Uma maneira relevante de se observar a concentração de renda, segundo o IBGE (2014), consiste em analisar os décimos de distribuição familiar per capita de rendimentos. Numa sociedade perfeitamente igualitária, cada décimo (10\% das pessoas com rendimentos) teria $10 \%$ da soma desses rendimentos. Com base no ano base de 2013, enquanto $10 \%$ da população brasileira mais pobre concentrava apenas $1,2 \%$ da renda total do país, no outro extremo, o décimo mais rico da população concentrava, durante o mesmo período, mais de $40 \%$ da totalidade da renda. Ainda sobre o rendimento familiar, em 2013, as famílias brasileiras com renda mensal per capita de até 1/4 de salário mínimo representavam $6,4 \%$ do total; com renda per capita de mais de $1 / 4$ até $1 / 2$, representavam $13,7 \%$ do total, e com renda per capita de mais de $1 / 2$ até um (1) salário mínimo, representavam $27,4 \%$ do total (IBGE, 2014). As faixas de renda per capita entre $1 / 4$ a um (1) salário mínimo correspondem, portanto, a mais de $\mathbf{4 7 \%}$ da população brasileira.
} 
de IDH baixo e muito baixo optam pela locação de caçambas de transportadores informais - em decorrência do menor custo - sendo, portanto, mais sujeitas à deposição irregular de RCC em vias e logradouros públicos no município de São Paulo.

É fato que a deposição irregular dos RCC, sendo muito mais intensa e extensiva nas periferias de São Paulo, reflete a forma desigual na espacialização dos problemas ambientais urbanos. O certo é que "[...] os problemas ambientais (ecológicos e sociais) não atingem igualmente todo o espaço urbano. Atingem muito mais os espaços físicos de ocupações das classes sociais menos favorecidas do que os das classes mais elevadas" (Coelho, 2001, p. 27). Ao contratar uma caçamba para coleta, transporte e destinação ambientalmente adequada dos RCC, o usuário, por um lado, estará internalizando os custos que seriam arcados pelo Poder Público caso esses resíduos fossem descartados incorretamente.

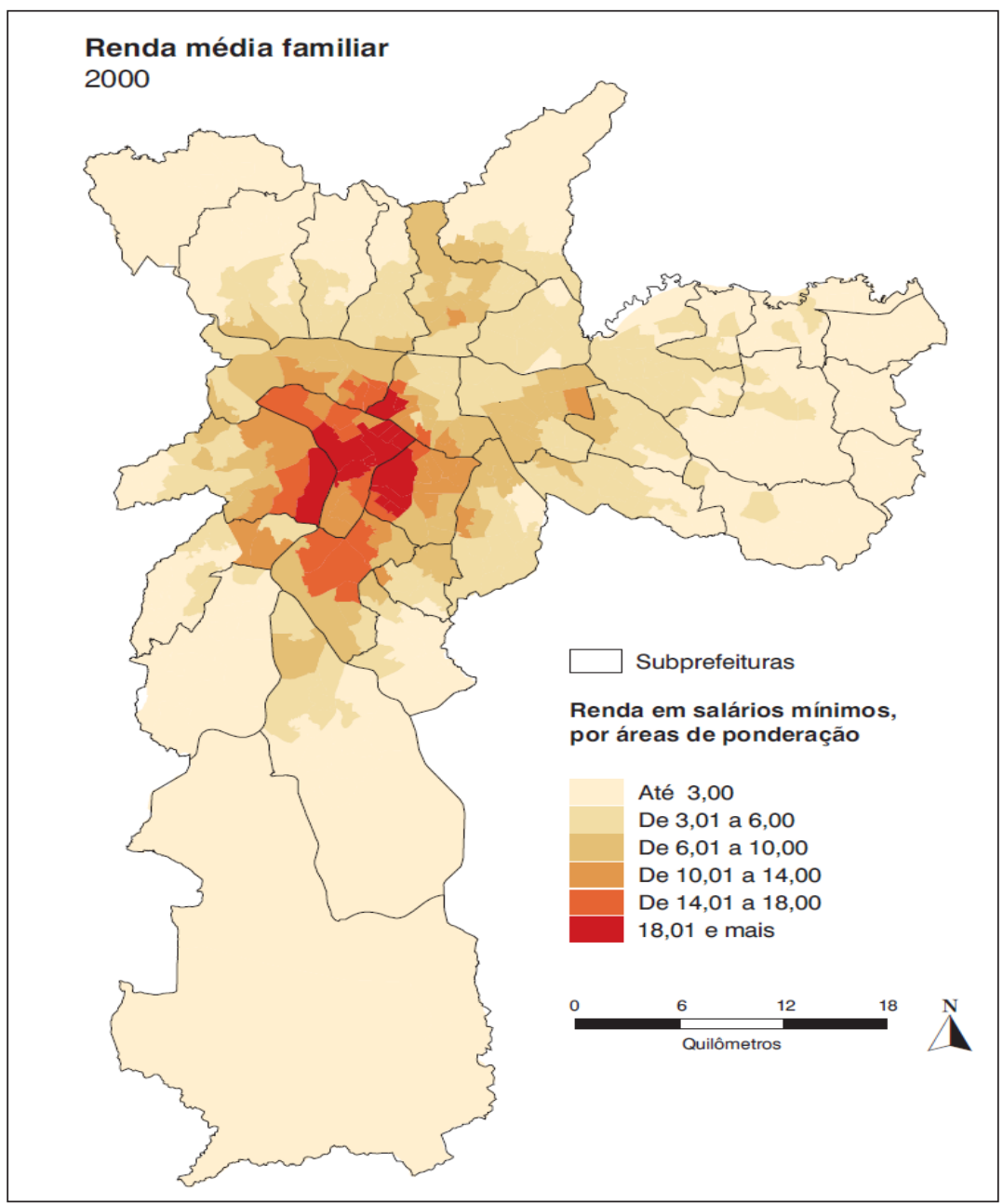

FIGURA 1 - Mapa da distribuição de renda no município de São Paulo no ano 2000. FONTE: São Paulo (2005) 


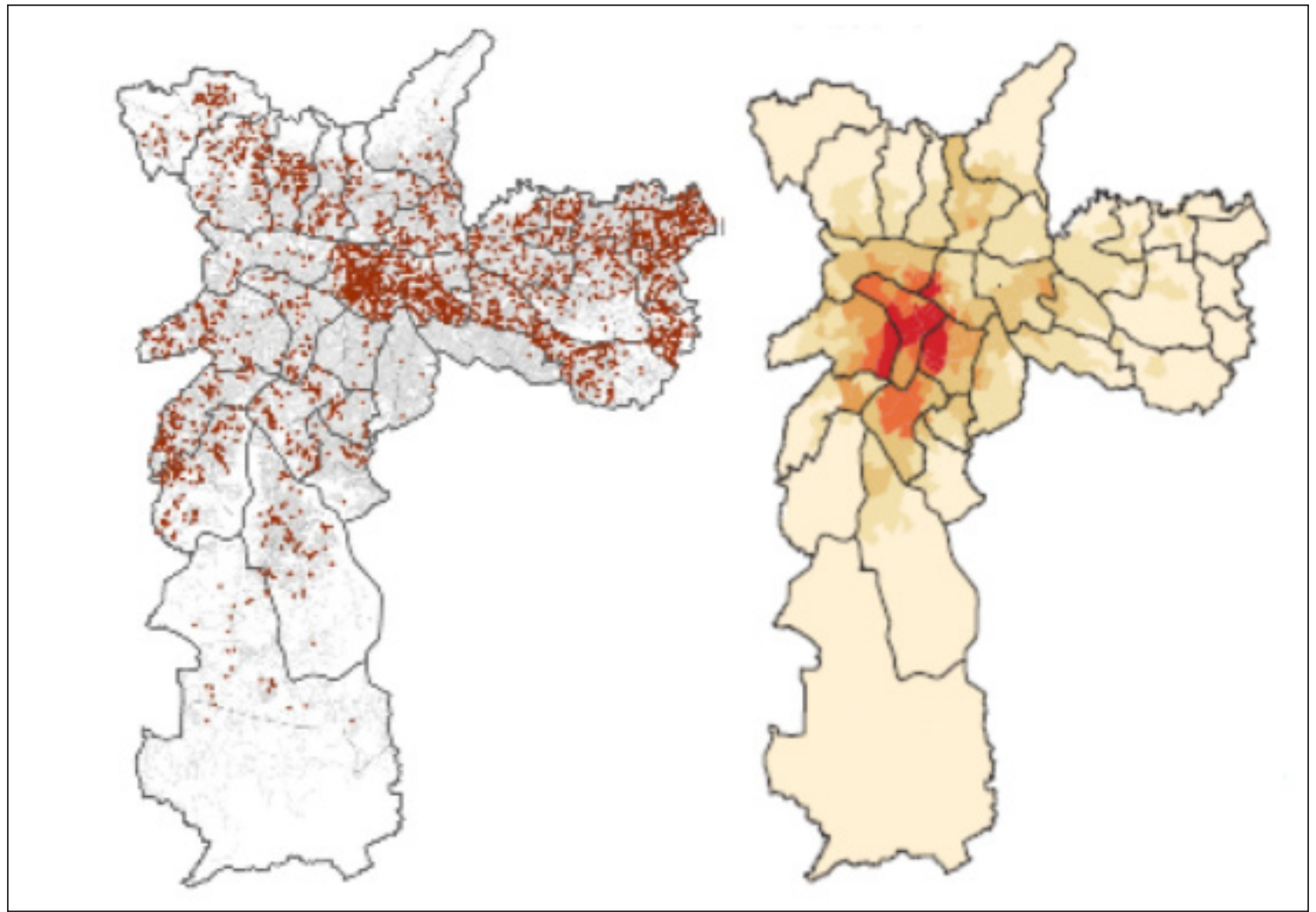

FIGURA 2 - Mapas comparativos entre a deposição irregular de RCC (à esquerda) e a distribuição de renda (à direita) no município de São Paulo.

FONTE: adaptado do PGIRS da Prefeitura de São Paulo (2014) e do mapa "valor do solo urbano” (São Paulo, 2005).

NOTA: os pontos em vermelho do mapa à esquerda seriam os locais com deposição irregular (pontos viciados).

Zona Norte (área azul escuro); Zona Leste (área vermelha); Centro (área amarela) e Zona Sul (área azul claro). Nota-se que, quanto mais longe da região de maior renda - Zona Oeste e uma pequena parte setentrional da Zona Sul (área verde) - maior a concentração de pontos irregulares.

Por outro lado, o usuário terá uma redução da sua renda para demandar outros bens ou serviços, implicando maior custo de oportunidade e reduzindo a maximização do seu bem-estar social, especialmente para o caso do usuário de baixa renda. Existem cerca de 379 empresas cadastradas na cidade de São Paulo como transportadoras de resíduos da construção civil, que oferecem esse serviço aos geradores por meio da locação de caçambas (São Paulo, 2014). A execução desse serviço é atualmente sob regime privado, mediante a modalidade de autorização, conforme art. 10, $2^{\circ}$, III, e art. 119, inciso II, da Lei Municipal n ${ }^{\circ}$ 13.478/02 (São Paulo, 2002). O website da prefeitura disponibiliza endereço e telefone para o gerador obter informações e contratar o serviço e, dessa maneira, assegurar (pelo menos a priori) que esses resíduos terão uma destinação ambientalmente adequada.

Uma das principais limitações no atual regime privado via autorização é permitir às empresas auto- 
rizatárias ampla liberdade na formação de preços e poucos mecanismos de controle sobre a quantidade, origem e destinação dos RCC. Como consequência, um dos causadores da deposição irregular, além dos geradores, são as próprias empresas de transporte, conforme mencionado no PGIRS (São Paulo, 2014, p. 137). Se, por um lado, as tarefas e atividades antes executadas pelo Estado foram transferidas para a iniciativa privada, com o suposto ganho de eficiência e de maior produtividade rotulado pelo new public management (Pollitt \& Bouckaert, 2011), paradigma que, nos países latino-americanos, teve maior intensidade a partir dos anos $1990 \mathrm{com}$ o advento das reformas neoliberais (CLAD, 2010), por outro, como salienta O'Toole (2003), quanto maior a descentralização e transferência de tarefas ao setor privado, por meio de parcerias público-privadas, concessão, privatização ou autorização, menor a efetividade nos mecanismos de controle por parte do órgão público. A Figura 3 sintetiza o atual fluxo da origem e geração dos principais fatores relacionados ao descarte irregular: geradores, PEVs, influência da renda para locação de caçambas e o precário controle sobre as empresas responsáveis pelo transporte.

Nesse sentido, o elevado número de empresas autorizadas para o transporte e execução desse serviço com base no regime de direito privado reduzem significativamente o poder e a capacidade de fiscalização da Autoridade Municipal de Limpeza Urbana (AMLURB), órgão público responsável pela gestão e fiscalização dos resíduos sólidos da cidade de São Paulo. Com efeito, o município não tem nenhum tipo de controle sobre quantas caçambas são alugadas diariamente, quem são os geradores que as alugam, onde se localizam e a quantidade de resíduos que geram. Isso é corroborado no próprio PGIRS, em que os dados sobre a geração de RCC são baseados apenas por estimativas:
[...] para a detecção do volume de resíduos gerados tem sido considerados ainda como indicadores: i) relações reconhecíveis em inventários realizados em municípios de médio porte, apontando sistematicamente a geração de RCC como o dobro da geração de resíduos domiciliares; ii) dedução da geração de RCC a partir do consumo aparente de agregados naturais (pedra britada e areia) pela população local, a partir de dados estimados pelo DNPM - Departamento Nacional da Produção Mineral.

[...] Os dados apresentados permitem considerar a hipótese de geração entre 18,5 e 24,6 mil toneladas diárias como bastante provável (São Paulo, 2014, p. 138-139, grifo nosso).

\section{Vantagens e ajustes necessários para a execução do transporte, tratamento e destinação final dos RCC com base no regime de direito público}

A universalização do serviço de coleta e transporte dos RCC, passando para o regime público para qualquer quantidade ou volume, tem um fator relevante de gerar receitas à municipalidade, exigindo-se, como contrapartida, o pagamento de taxas pelos geradores. Um dos critérios que deve nortear as faixas de cobrança seria o nível de renda: poderiam ser criadas faixas de cobrança, aplicadas de acordo com o valor venal do imóvel, com base na renda familiar per capita (como apresentado na seção anterior). Outra definição necessária para precificar os serviços refere-se ao pequeno e grande gerador: atualmente, a Lei Municipal no 13.478/02 (São Paulo, 2002) determina que quantidades acima de $50 \mathrm{~kg} / \mathrm{dia}$ de RCC ou 200 litros/dia de resíduos volumosos são de responsabilidade do grande gerador conforme art. 139, inciso II (São Paulo, 2002). A Figura 4 apresenta uma proposta sobre a instituição do regime de direito público na gestão dos RCC e a remuneração mediante taxa, atuando sobre três questões: i) o custo para locação de caçambas; ii) 


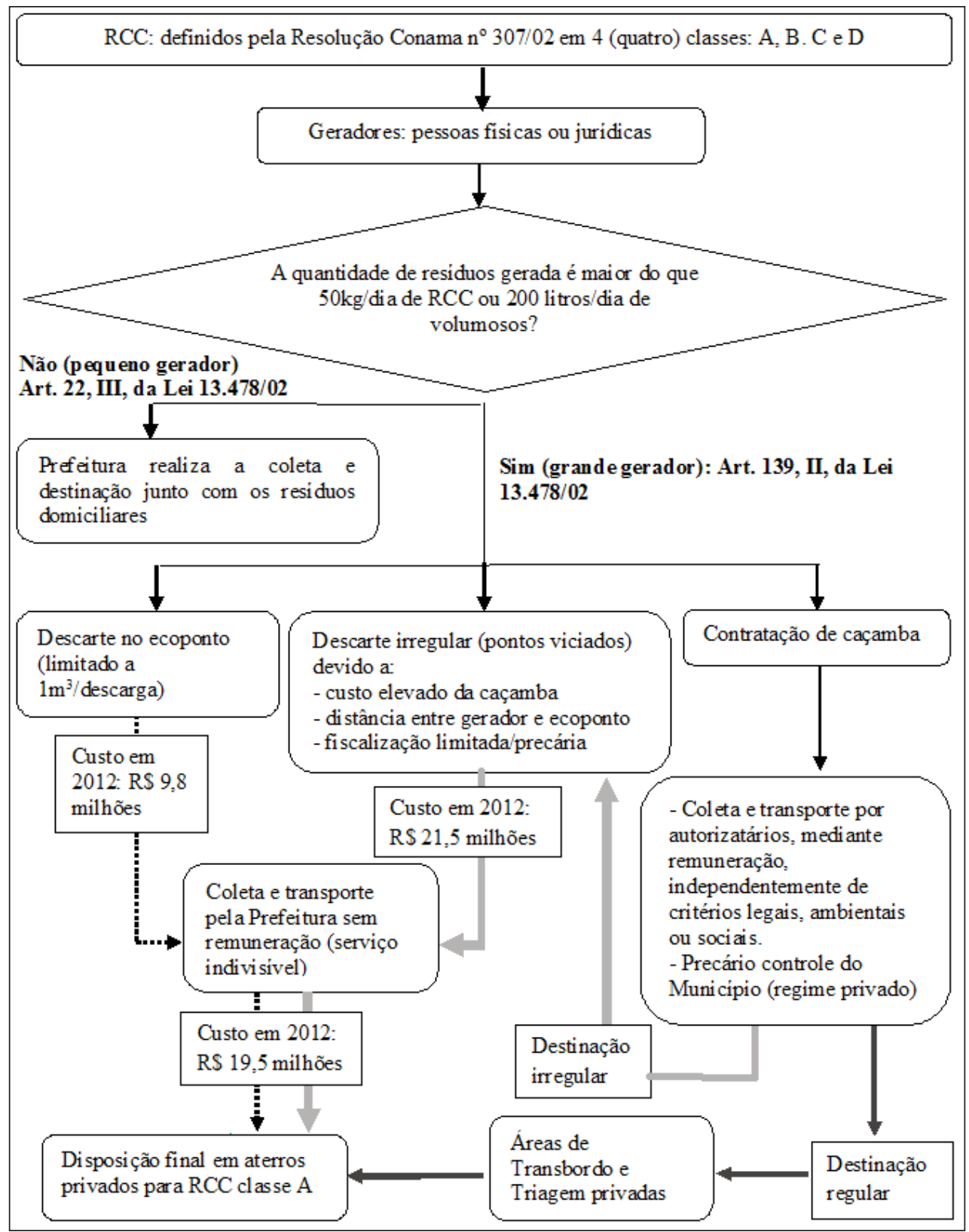

FIGURA 3 - Diagnóstico e situação atual do fluxo dos resíduos da construção civil e resíduos volumosos no município de São Paulo. Setas claras (descarte irregular) e setas tracejadas (descarte regular pelos ecopontos) indicam a proporção de resíduos e custos ao município. Setas escuras (serviço privado) possuem uma espessura menor em relação às setas claras, indicando parte dos resíduos que estão sendo atualmente transferidos para o descarte irregular devido ao custo elevado à população de baixa renda e limitação no controle dos autorizatários (empresas responsáveis pelo transporte).

FONTE: elaboração própria a partir do PGIRS (São Paulo, 2014). 
maior controle sobre as empresas de transporte; e iii) maior eficiência no controle sobre os grandes geradores.

Para os pequenos geradores, a instituição de taxas para a execução dos serviços poderia adotar como principal critério o nível de renda dos indivíduos, utilizando-se faixas de precificação de acordo com a localização do imóvel (conforme Figura 1). Como apontado por Vergara \& Tchobanoglus (2012) e Yu et al. (2013), a instituição de sobrepreço como taxas para descartar os resíduos pode influenciar os geradores a adotarem medidas para reduzir, reaproveitar ou reciclar ou, por outro lado, externalizá-los ilegalmente como meio racional de transferir os custos ao Poder Público.

No caso do município de São Paulo, o atual regime de direito privado permite às empresas total liberdade para adotarem o preço que for conveniente para ofertar a locação de caçambas, impedindo ou limitando uma parte dos geradores a demandar por tal serviço. Por isso, a sugestão de que, com uma faixa crescente de precificação, haveria uma drástica redução no despejo irregular pela maior capacidade dos geradores de internalizarem os custos (como indicada na Figura 4 quando comparada com a atual situação representada pela Figura 3). Além disso, a redução de custos na locação de caçambas para os usuários de menor renda lhes traria uma alternativa em relação às dificuldades logísticas para acessarem os ecopontos.

A execução dos serviços de coleta de RCC mediante concessão ou permissão poderia ser feita por diversas empresas privadas, após o processo de licitação pública. Poderia, ainda, ser por contrato administrativo (como já é realizado para a coleta de resíduos domiciliares em muitos municípios brasileiros): neste caso, a empresa seria contratada e remunerada diretamente pelo Poder Público (diferente da concessão, que é remunerada pelo usuário, mediante pagamento de tarifa). No caso de contrato administrativo, o Poder Público cobraria a prestação do serviço realizado ao usuário por meio de taxa, podendo então precificá-la com base nos critérios e princípios que possam garantir a eficiência, modicidade e capacidade de pagamento dos usuários. Ao mesmo tempo, haveria um maior controle sobre as etapas de coleta, transporte e destinação desses resíduos, com a mediação do órgão municipal entre o gerador e empresa responsável pelo transporte.

O município precisaria considerar de maneira mais explícita a definição dos critérios e procedimentos para os pequenos e grandes geradores. Com base na lei atual do município de São Paulo (13.478/02), os grandes geradores são tipificados quando geram acima de $50 \mathrm{~kg} / \mathrm{dia}$ de RCC ou 200 litros/dia de volumosos (São Paulo, 2002). Já a Lei municipal no 14.803/08, no art. 22 (São Paulo, 2008), determina a obrigatoriedade aos grandes geradores - independentemente do tipo, porte ou grau de impacto ambiental do empreendimento - em elaborar e implementar o Plano de Gerenciamento de Resíduos Sólidos (PGRS) para quantidades geradas acima de $1 \mathbf{m}^{3}$ e que necessitarem de alvará de aprovação e execução de edificação nova, de reforma ou reconstrução, de demolição e de movimento de terra, nos termos da Lei Municipal no 11.228/92 (São Paulo, 1992). Entretanto, apenas as empresas de construção civil são definidas como grandes geradores para tais tipos de resíduos, conforme art. 20, inciso III, da PNRS (Brasil, 2010c), reiterado no próprio PGIRS do município de São Paulo (São Paulo, 2014, p. 146). Portanto, há um conflito entre as leis municipais $n^{\circ}$ 13.478/02 e 14.803/08 e a Política Nacional de Resíduos Sólidos (PNRS) para a definição do pequeno e grande gerador, incluindo critérios para este último, relacionados à obrigatoriedade na elaboração do Plano de Gerenciamento de Resíduos Sólidos (PGRS). 


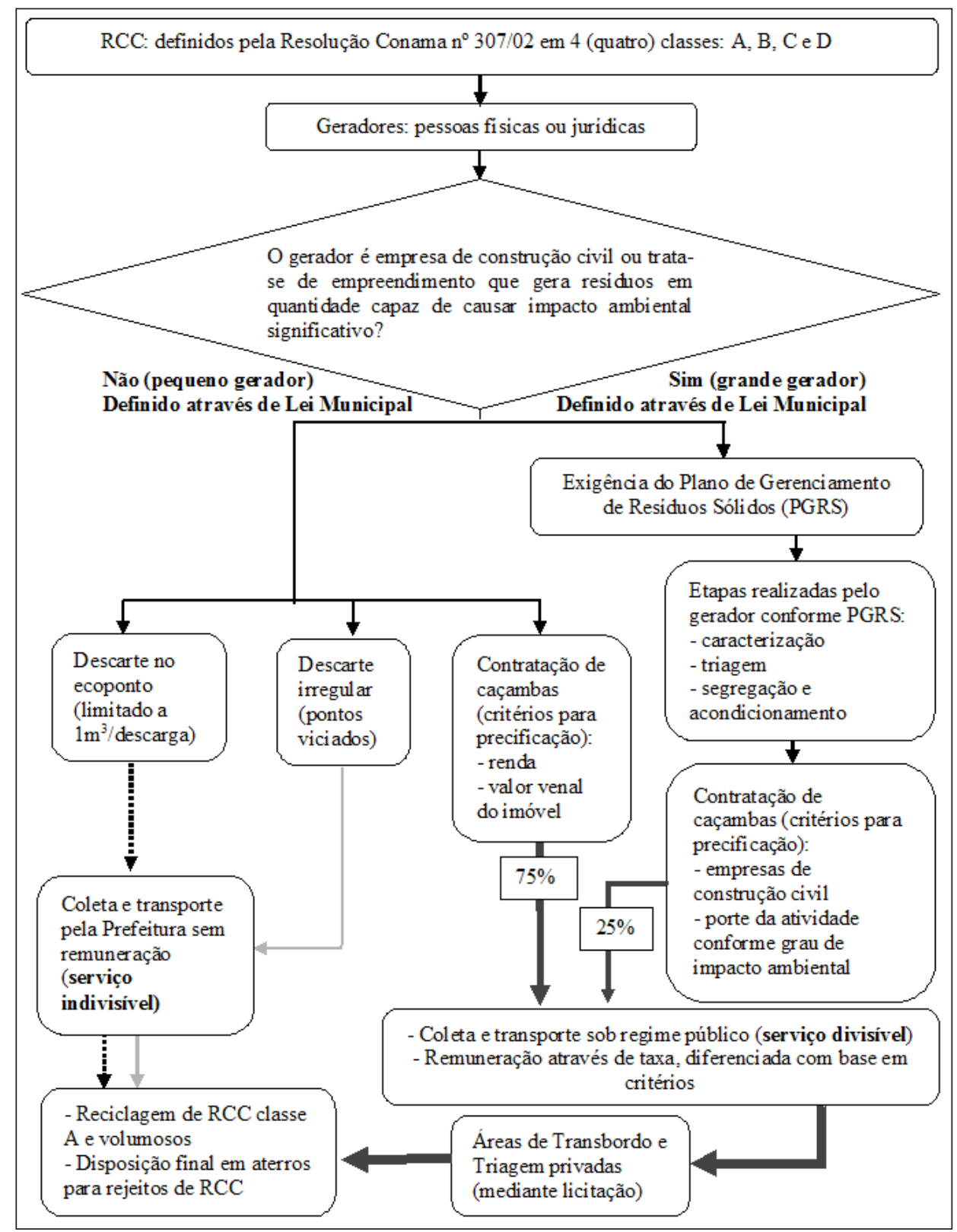

FIGURA 4 - Situação pretendida para o fluxo de RCC e resíduos volumosos, por meio do regime de direito público para coleta e transporte. Espessura das setas claras (serviço indivisível) em relação às setas escuras (serviço divisível) indica a proporção de resíduos e custos da deposição irregular que seriam reduzidos devido aos menores custos para população de baixa renda demandar as caçambas e aumento do controle sobre as empresas de transporte. O percentual das setas $(75 \%$ e $25 \%)$ refere-se à proporção estimada entre pequeno e grande gerador, conforme Pinto (2005) e Ministério do Meio Ambiente (Brasil, 2012), respectivamente. Setas tracejadas (serviço indivisível) indicam o descarte regular por meio dos ecopontos (PEVs).

FONTE: elaboração própria. 
Em relação aos grandes geradores (inclusive empresas de construção civil), uma alternativa que pode ser implementada para defini-los seria com base na quantidade de resíduos gerados, considerando-se ainda o tipo, característica do empreendimento e grau de impacto ambiental. Assim, a solicitação de alvará para obras de grande porte, incluindo novas edificações e demolições (conforme Lei Municipal $\mathrm{n}^{\mathrm{o}} 11.228 / 92$ ), deveria basear-se apenas para obras de impacto ambiental significativo. As etapas de segregação dos resíduos na obra e acondicionamento seriam uma parte do Plano de Gerenciamento de Resíduos Sólidos (PGRS), conforme art. 20, inciso III, da PNRS, e disciplinado pelo art. $9^{\circ}$ da Resolução CONAMA no 307/02, a qual determina que tal plano, de responsabilidade do grande gerador, deve incluir as etapas de caracterização (inciso I), triagem (inciso II), acondicionamento (inciso III), transporte (inciso IV) e destinação (inciso V). As etapas de caracterização, triagem e acondicionamento seriam realizadas pelo grande gerador; já as etapas de transporte e destinação seriam executadas pelo município (diretamente ou indiretamente, por intermédio do setor privado, seja por concessão, permissão ou por contrato administrativo), devidamente remuneradas mediante taxa.

A possibilidade do município em executar algumas etapas do gerenciamento de resíduos dos grandes geradores inerente ao transporte, tratamento e destinação final, desde que devidamente remunerados, está prevista no art. $27, \S 2^{\circ}$, da PNRS:

$\S 2^{\circ}$ Nos casos abrangidos pelo art. 20, as etapas sob responsabilidade do gerador que forem realizadas pelo poder público serão devidamente remuneradas pelas pessoas físicas ou jurídicas responsáveis, observado o disposto no $\S 5^{\circ}$ do art. 19 (Brasil, 2010c).

\section{Considerações finais}

Em resposta ao objetivo proposto, os resultados do estudo revelam que os principais fatores relacionados à deposição irregular por parte das empresas de transporte de RCC podem ser decorrentes do precário controle da AMLURB. Atualmente, a execução do serviço de coleta de RCC, com base no regime de direito privado, dificulta uma atuação, controle e monitoramento mais incisivos. Sem informações para monitorar quem aluga as caçambas, qual a quantidade de resíduos gerada e por quem (pequeno ou grande gerador) e o tratamento destinado a esses resíduos, pode-se estar favorecendo a deposição irregular por parte dessas empresas. Se a AMLURB não possui tais informações e mecanismos de controle sobre a geração, coleta, transporte e disposição em aterro, torna-se difícil garantir que os RCC sejam destinados prioritariamente para o reaproveitamento ou reciclagem, tal como determinado pela PNRS.

Já os principais fatores relacionados à deposição irregular por parte dos geradores associam-se a variáveis e atributos, como renda para a locação de caçambas e acessibilidade até os ecopontos (PEVs). A proposta de incluir os critérios e princípios de eficiência, modicidade, benefício, capacidade de pagamento, equidade e universalidade nas etapas de gerenciamento dos RCC, sobretudo na coleta, transporte e tratamento, poderia propiciar uma gestão integrada dos RCC e resíduos volumosos, numa ótica redutora de impactos socioambientais.

A ocupação de assentamentos degradados como favelas, cortiços e casas precárias na periferia, apesar de caracterizados em ambientes insalubres, com carências de diversas naturezas - incluindo o acesso aos serviços públicos urbanos como transporte, habitação e saneamento - representa uma 
forma de sobrevivência no contexto de segregação urbana. Dessa maneira, o estabelecimento de taxas diferenciadas para a locação de caçambas pode ser um importante mecanismo de acesso ao serviço de limpeza urbana à população vulnerável. O elevado custo social para demandar a locação de caçambas implica uma maior dificuldade para as famílias de baixa renda, as quais, consequentemente, tenderão a externalizar esse custo por meio do descarte irregular nos pontos viciados. Além disso, a cobrança de acordo com faixas diferenciadas de renda traria redução dos custos à municipalidade, dada a menor ocorrência do despejo irregular.

Os pequenos geradores poderiam ter as seguintes possibilidades de destinação dos RCC: por meio do descarte nos PEVs limitados a no máximo $1 \mathrm{~m}^{3} /$ descarga ou pela contratação de caçambas que, mesmo para volumes superiores a $1 \mathrm{~m}^{3} / \mathrm{dia}$, continuariam sendo enquadrados como pequenos geradores e assim ficariam dispensados da elaboração e apresentação do Plano de Gerenciamento de Resíduos Sólidos (PGRS).

Os grandes geradores poderiam fazer uso do mesmo serviço de coleta e transporte por meio da locação de caçambas (aliás, como já o fazem atualmente), porém, somente para estes seria exigido o PGRS. No plano dos grandes geradores, seria necessário especificar os procedimentos relacionados à caracterização, triagem e armazenamento dos

\section{Referências}

Agopyan, V.; John, V. M. O desafio da sustentabilidade na construção civil. Goldemberg, J. (Coord.). São Paulo: Blucher, 2011. v. 5.

Brasil. Lei n ${ }^{\circ}$ 6.938, de 31 de agosto de 1981. Dispõe sobre a Política Nacional de Meio Ambiente, seus fins e mecanismos de formulação e aplicação, e dá outras providências. Brasília: DOU de 02/09/1981.
RCC, podendo ainda servir de subsídios no processo administrativo de licenciamento ambiental, de acordo com o órgão municipal competente. Para os grandes geradores, também haveria a necessidade de níveis de precificação gradual pela contratação dos serviços de coleta e transporte, conforme o tipo, porte, característica do empreendimento e nível de impacto ambiental (pouco ou muito significativo), contemplando, dessa maneira, os princípios da proporcionalidade e razoabilidade.

$\mathrm{O}$ estudo identificou ainda divergências na definição do pequeno e grande gerador, além da destinação de RCC junto com resíduos domésticos para aterros sanitários, contrariando a ordem de prioridade estabelecida pela PNRS (Brasil, 2010). Todos esses ajustes requerem alteração na legislação atual do município.

Por fim, para os estudos futuros, propõe-se a realização de estudos comparados em municípios de diferentes portes, regiões geográficas do país e índice de desenvolvimento humano (IDH), para entender com maior acurácia a relação de instrumentos econômicos no contexto da deposição irregular de RCC no Brasil.

\section{Agradecimentos}

À Agência CAPES pela bolsa de pesquisa para o apoio à Dissertação de Mestrado.

Brasil. Fundação Nacional de Saúde - FUNASA. Programas municipais de coleta seletiva de lixo como fator de sustentabilidade dos sistemas públicos de saneamento ambiental na Região Metropolitana de São Paulo. Brasília: Fundação Nacional de Saúde, 2010a.

Brasil. Ministério do Meio Ambiente - MMA. Manual para Implantação de Sistema de Gestão de Resíduos de 
Construção Civil em Consórcios Públicos. Brasília, DF: Secretaria de Recursos Hídricos e Ambiente Urbano, 2010 b.

Brasil. Lei ${ }^{\circ} 12.305$, de 2 de agosto de 2010. Institui a Política Nacional de Resíduos Sólidos; altera a Lei no 9.605 , de 12 de fevereiro de 1998; e dá outras providências. Brasília: DOU de 03/08/2010 [2010c].

Brasil. Decreto $n^{\circ} 7.217$, de 21 de junho de 2010. Regulamenta a Lei $\mathrm{n}^{\circ} 11.445$, de 5 de janeiro de 2007, que estabelece diretrizes nacionais para o saneamento básico e dá outras providências. Brasília: DOU de 22/06/2010 [2010d].

Brasil. Ministério do Meio Ambiente. Planos de gestão de resíduos sólidos: manual de orientação Brasília, 2012. Disponível em: <http://www.mma.gov.br/estruturas/253/_publicacao/253_publicacao09042012101719.pdf > . Acesso em: abr. 2012.

Brasil. Ministério das Cidades. PLANSAB (Plano Nacional de Saneamento Básico): mais saúde com qualidade de vida e cidadania. Brasília, 2014.

Calado, S.; Ferreira, S.C. Análise de documentos: método de recolha e análise de dados. Metodologia de Investigação I. DEFCUL. 2004-2005.

Carrijo, P. M. Análise da influência da massa especifica de agregados graúdos provenientes de resíduos de construção e demolição no desempenho mecânico do concreto. São Paulo, Dissertação (Mestrado em Engenharia Civil) - Escola Politécnica da Universidade de São Paulo, 2005.

Carvalho Filho, J. S. Manual de Direito Administrativo. 15. ed. Rio de Janeiro: Lumen Juris, 2006.

Cervo, A. L.; Bervian, P. A.; Silva, R. Metodologia cientifca. 6. ed. São Paulo: Pearson Prentice Hall, 2007.

CLAD - Centro Latinoamericano de Administración para el Desarrollo. Gestión Pública Iberoamericana para el siglo XXI. XL Reunión Ordinaria del Consejo Directivo del CLAD. Santo Domingo, Republica Dominicana, 8-9 noviembre, 2010.

Coelho, M. C. N. Impactos ambientais em áreas urbanas teorias, conceitos e métodos de pesquisa. In: Guerra, A. J. T.; Cunha, S. B. (Orgs.). Impactos ambientais urbanos no Brasil. 1. ed., v. 1. Rio de Janeiro: Bertrand Brasil, 2001. p. 19-45.

CONAMA - Conselho Nacional de Meio Ambiente. Resolução $n^{\circ}$ 307, de 5 de julho de 2002. Brasília: DOU de 17/07/2002.
Delongui, L. et al. Panorama dos resíduos da construção civil na região central do Rio Grande do Sul. Teoria e Prática na Engenharia Civil, 18, 71-80, 2011.

Feijão Neto, F. G. Deposições irregulares de resíduos da construção civil na cidade de Parnaiba-PI. Rio Claro, Dissertação (Mestrado em Geografia) - UNESP, 2010.

Figueiredo, L. V. A saúde Pública na Constituição e as operadoras de planos de saúde. In: Bacellar Filho, R. F. (Coord.). Direito administrativo contemporâneo: estudos em memória do Professor Manoel de Oliveira Franco Sobrinho. Belo Horizonte: Fórum, 2004. p. 167-183.

Hao, J. L.; Hills, M. J.; Tam, V. W. Y. The effectiveness of Hong Kong's Construction Waste Disposal Charging Scheme. Waste Management \& Research, 26, 553-558, 2008. doi: 10.1177/0734242X07085345

IBGE - Instituto Brasileiro de Geografia e Estatística. Síntese de indicadores sociais: uma análise das condições de vida da população brasileira. Rio de Janeiro, 2014.

IPEA - Instituto de Pesquisa Econômica Aplicada. Diagnóstico dos Resíduos Sólidos da Construção Civil. Relatório de Pesquisa. Brasília, 2012.

Jacobi, P. R. Impactos socioambientais urbanos: do risco à busca de sustentabilidade. In: Mendonça, F. (Ed.). Impactos socioambientais urbanos. Curitiba: Editora UFPR, 2004. p. $169-184$.

Jacobi, P. R.; Besen, G. R. Gestão dos resíduos sólidos em São Paulo: desafios da sustentabilidade. Estudos Avançados, 25(71), 135-155, 2011. Disponível em: <http:// www.scielo.br/scielo.php?script=sci_arttext\&pid=S010340142011000100010\&lng=en\& $\mathrm{nrm}=$ iso $>$

Karpinsk, L. A. et al. Gestão diferenciada de resíduos da construção civil: uma abordagem ambiental. Porto Alegre: Edipucrs, 2009. Disponível em: <http://www.pucrs.br/ orgaos/edipucrs/>. Acesso em: out. 2015.

Lu, W.; Tam, V. W. Y. Construction waste management policies and their effectiveness in Hong Kong: A longitudinal review. Renewable and Sustainable Energy Reviews, 23, 214-223, 2013. doi: 10.1016/j.rser.2013.03.007

Margulis, S. A regulamentação ambiental: instrumentos e implementação. Rio de Janeiro: IPEA, 1996. 
Mello, C. A. B. Serviço público e poder de polícia: concessão e delegação. Revista Eletrônica de Direito do Estado, 7, 2006.

Morais, G. M. D. Diagnóstico da deposição clandestina de resíduos de construção e demolição em bairros periféricos de Uberlândia: subsídios para uma gestão sustentável. Uberlândia, Dissertação (Mestrado em Engenharia Civil) - Universidade Federal de Uberlândia, 2006.

Mourão, S. A.; Aragão, V. R.; Damasceno, D. A. P. M. Diagnóstico da disposição dos resíduos sólidos da construção civil na cidade de Montes Claros, MG. Ciência e Natura, 37(42), 251-261, 2015. doi: 105902/2179460X17895

Mueller, C. C. Os economistas e as relações entre o sistema econômico e o meio ambiente. Brasília: Universidade de Brasília: Finatec, 2007.

Osmani, M. Construction Waste Minimization in the UK: Current Pressures for Change and Approaches. Procedia-Social and Behavioral Sciences, 40, 37-40, 2012. doi: 10.1016/j.sbspro.2012.03.158

O’Toole, L. J. Jr. Interorganizacional relations in implementation. In: Peters, B. G.; Pierre, J. (Eds.). Handbook of public administration. London: SAGE Publications, 2003. p. 234-244.

Paiva, C. C.; Paiva, S. F. Fundamentos básicos da economia do setor público. In: Vian, C. E. F. (Org.). Introdução à economia. Campinas, SP: Alínea, 2009. p. 277-301.

Pinto, T. P. (Coord.). Gestão ambiental de resíduos da construção civil: a experiência do SindusCon-SP. São Paulo: Obra Limpa; I\&T; SindusCon-SP, 2005.

Pollitt, C.; Bouckaert, G. Public management reform: a comparative analysis. 3. ed. Oxford: Oxford University, 2011.

Ribeiro, F. A. B. S.; Dias, J. F. Deposição irregular dos resíduos de construção civil em Uberlândia/MG. Revista Nacional de Gerenciamento de Cidades, 1(5), 88-106, 2013.

São Paulo (Município). Lei $n^{\circ} 13.478$, de 30 de dezembro de 2002. Dispõe sobre a organização do Sistema de Limpeza Urbana do Município de São Paulo; cria e estrutura seu órgão regulador; autoriza o Poder Público a delegar a execução dos serviços públicos mediante concessão ou permissão; institui a Taxa de Resíduos Sólidos Domiciliares TRSD, a Taxa de Resíduos Sólidos de Serviços de Saúde
TRSS e a Taxa de Fiscalização dos Serviços de Limpeza Urbana FISLURB; cria o Fundo Municipal de Limpeza Urbana FMLU, e dá outras providências. Secretaria de Governo Municipal: 30/12/2002.

São Paulo (Município). Mapa do Solo Urbano. 2005. Disponível em: $<$ http://smdu.prefeitura.sp.gov.br/panorama/>. Acesso em: ago. 2015.

São Paulo (Município). Lei $n^{\circ} 14.803$, de 26 de junho de 2008. Dispõe sobre o Plano Integrado de Gerenciamento dos Resíduos da Construção Civil e Resíduos Volumosos e seus componentes, o Programa Municipal de Gerenciamento e Projetos de Gerenciamento de Resíduos da Construção Civil conforme previstos na Resolução CONAMA n 307/2002, disciplina a ação dos geradores e transportadores destes resíduos no âmbito do Sistema de Limpeza Urbana do Município de São Paulo e dá outras providências. Secretaria de Governo Municipal: 26/06/2008.

São Paulo (Município). Comitê Intersecretarial para a Política Municipal de Resíduos Sólidos. Plano de Gestão integrada de Resíduos Sólidos da Cidade de São Paulo. São Paulo, 2014. Disponível em: <http://www.prefeitura. sp.gov.br/cidade/secretarias/upload/servicos/arquivos/ PGIRS-2014.pdf $>$. Acesso em: fev. 2015.

Sayago, D. E.; Oliveira, J. M. D.; Seroa da Motta, R. Resíduos sólidos: propostas de instrumentos econômicos ambientais. Brasília: Ministério do Planejamento, Secretaria de Política Urbana, 1998.

Schneider, D. M. Deposições irregulares de resíduos da construção civil na cidade de São Paulo. São Paulo, Dissertação (Mestrado em Saúde Pública) - Faculdade de Saúde Pública da Universidade de São Paulo, 2003.

Seroa da Motta, R. Economia ambiental. Rio de Janeiro: FGV, 2006.

Silva, A. A. Avaliação dos pontos de apoio (ecopontos) na gestão dos resíduos sólidos urbanos: estudo de caso de São José do Rio Preto - SP. São Carlos, Dissertação (Mestrado em Engenharia Urbana) - Universidade Federal de São Carlos, 2012.

Strauss, A. L.; Corbin, J. Pesquisa qualitativa: técnicas e procedimentos para o desenvolvimento. 1. ed. Porto Alegre: Artmed, 2008. 288 p. 
UNEP - United Nations Environment Program. Year book: emerging issues in our global environment. Kenya, 2014.

Vergara, S. E.; Tchobanoglous, G. Municipal Solid Waste and the Environment: A Global Perspective. The Annual Review of Environment and Resources, 37, 277-309, 2012. doi: 10.1146/annurev-environ-050511-122532

Wu, X.; Ramesh, M.; Howlett, M.; Fritzen, S. Guia de políticas públicas: gerenciando processos. Tradução de Ricardo Avelar de Souza. Brasília: Enap, 2014.
Yeheyis, M.; Hewage, K.; Alam, M. S.; Eskicioglu, C.; Sadiq, R. An overview of construction and demolition waste management in Canada: a lifecycle analysis approach to sustainability. Clean Technologies and Environmental Policy, 15, 81-91, 2013. doi: 10.1007/s10098-012-0481-6 Yu, A. T. W.; Poon, C. S.; Wong, A.; Yip, R.; Jaillon, L. Impact of Construction Waste Disposal Charging Scheme on work practices at construction sites in Hong Kong. Waste Management, 33, p.138-146, 2013. 